

\title{
Application of Decline Curve Analysis To Estimate Recovery Factors for Carbon Dioxide Enhanced Oil Recovery
}

By Hossein Jahediesfanjani

Chapter $\mathrm{C}$ of

Three Approaches for

Estimating Recovery Factors in

Carbon Dioxide Enhanced Oil Recovery

Mahendra K. Verma, Editor

Scientific Investigations Report 2017-5062-C 


\title{
U.S. Department of the Interior RYAN K. ZINKE, Secretary
}

\section{U.S. Geological Survey William H. Werkheiser, Acting Director}

\author{
U.S. Geological Survey, Reston, Virginia: 2017
}

For more information on the USGS — the Federal source for science about the Earth, its natural and living resources, natural hazards, and the environment-visit https://www.usgs.gov or call 1-888-ASK-USGS.

For an overview of USGS information products, including maps, imagery, and publications, visit https://store.usgs.gov.

Any use of trade, firm, or product names is for descriptive purposes only and does not imply endorsement by the U.S. Government.

Although this information product, for the most part, is in the public domain, it also may contain copyrighted materials as noted in the text. Permission to reproduce copyrighted items must be secured from the copyright owner.

Suggested citation:

Jahediesfanjani, Hossein, 2017, Application of decline curve analysis to estimate recovery factors for carbon dioxide enhanced oil recovery, chap. C of Verma, M.K., ed., Three approaches for estimating recovery factors in carbon dioxide enhanced oil recovery: U.S. Geological Survey Scientific Investigations Report 2017-5062, p. C1-C20, https://doi.org/10.3133/sir20175062C. 


\section{Contents}



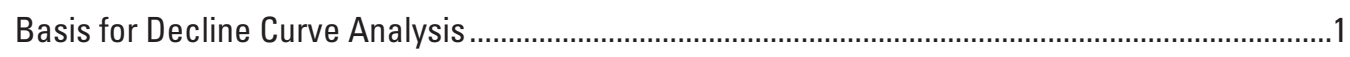

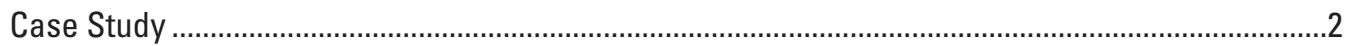





Appendix C1. Decline Curve Analysis of Selected Reservoirs .......................................................

\section{Figures}

C1. Semi-log plot of the oil production rate versus the oil production time for the San Andres Limestone in the Sable oil field in the west Texas section of the Permian Basin Province, showing the decline trends for both the waterflood and the carbon dioxide enhanced oil recovery $\left(\mathrm{CO}_{2}\right.$-EOR) phases

C2. Graph of the oil production rate versus the cumulative oil production for the San Andres Limestone in the Sable oil field, Texas, showing the decline trends for both the waterflood and the carbon dioxide enhanced oil recovery $\left(\mathrm{CO}_{2}\right.$-EOR) phases.

C3. Bar graph showing the number of studied reservoirs having values of additional oil recovery factors due to carbon dioxide enhanced oil recovery $\left(\mathrm{CO}_{2}\right.$-EOR) in five different ranges

C1-1 to $\mathrm{C} 1-15$. Graphs of the oil production rate versus the cumulative oil production showing the decline trends for both the waterflood and the carbon dioxide enhanced oil recovery $\left(\mathrm{CO}_{2}\right.$-EOR) phases for the-

C1-1. San Andres Limestone in the Sable oil field, Texas...............................13

C1-2. Weber Sandstone in the Rangely oil field, Colorado...............................14

C1-3. Tensleep Formation in the Lost Soldier oil field, Wyoming ....................14

C1-4. Madison Formation in the Lost Soldier oil field, Wyoming....................15

C1-5. San Andres Limestone in the Wasson oil field, Texas ............................15

C1-6. Clear Fork Group in the Wasson oil field, Texas.....................................16

C1-7. Thirtyone Formation in the Dollarhide oil field, Texas............................16

C1-8. Clear Fork Group in the Dollarhide oil field, Texas................................17

C1-9. "Canyon-age reservoir" in the Salt Creek oil field, Texas......................17

C1-10. San Andres Limestone in the Seminole oil field, Texas .........................18

C1-11. Sandstone of the Ramsey Member of the Bell Canyon Formation in the Twofreds oil field, Texas...............................................18

C1-12. San Andres Limestone in the Vacuum oil field, New Mexico................19

C1-13. San Andres Limestone in the Cedar Lake oil field, Texas.......................19

C1-14. San Andres Limestone in the North Hobbs oil field,



C1-15. San Andres Limestone in the Yates oil field, Texas ...............................20 


\section{Tables}

C1. Best match values of the initial oil production rate, the initial decline rate for oil production, and the corresponding coefficient of determination $\left(R^{2}\right)$ values for both waterflood and carbon dioxide enhanced oil recovery $\left(\mathrm{CO}_{2}-\mathrm{EOR}\right)$ decline periods of the studied reservoirs

C2. Additional oil recovery factors estimated by using decline curve analysis for carbon dioxide enhanced oil recovery $\left(\mathrm{CO}_{2}\right.$-EOR) projects in 15 selected

reservoirs 


\title{
Chapter C. Application of Decline Curve Analysis To Estimate Recovery Factors for Carbon Dioxide Enhanced Oil Recovery
}

\author{
By Hossein Jahediesfanjani'
}

\section{Background}

In the decline curve analysis (DCA) method of estimating recoverable hydrocarbon volumes, the analyst uses historical production data from a well, lease, group of wells (or pattern), or reservoir and plots production rates against time or cumulative production for the analysis. The DCA of an individual well is founded on the same basis as the fluid-flow principles that are used for pressure-transient analysis of a single well in a reservoir domain (Fetkovich, 1987; Fetkovich and others, 1987) and therefore can provide scientifically reasonable and accurate results. However, when used for a group of wells, a lease, or a reservoir, the DCA becomes more of an empirical method. Plots from the DCA reflect the reservoir response to the oil withdrawal (or production) under the prevailing operating and reservoir conditions, and they continue to be good tools for estimating recoverable hydrocarbon volumes and future production rates. For predicting the total recoverable hydrocarbon volume, the DCA results can help the analyst to evaluate the reservoir performance under any of the three phases of reservoir productive life - primary, secondary (waterflood), or tertiary (enhanced oil recovery) phases - so long as the historical production data are sufficient to establish decline trends at the end of the three phases.

\section{Basis for Decline Curve Analysis}

The DCA method is used to predict the future oil production rate of an oil-producing well or reservoir. Theoretically, according to this method, the oil production rate for a given entity will first reach its maximum output and then decline according to the following generalized relationship (Fetkovich, 1987):

$$
\frac{q}{q_{i}}=\left(1+b D_{i} t\right)^{-\frac{1}{b}}
$$

where

$q$ is the time-dependent oil production rate, in barrels per day (bbl/day);

$q_{i} \quad$ is the initial oil production rate, in barrels per day;

$D_{i} \quad$ is the initial decline rate per year;

$b$ represents the degree of curvature of the shape of the decline trend,

which is dimensionless; and

$t$ is the oil production time, in years.

Theoretically, the parameters, such as $q_{i}, D_{i}$, and $b$, have defined meanings only if equation $\mathrm{C} 1$ is applied for a single well that produces from a single reservoir under appropriate fluid-flow conditions. However, if equation $\mathrm{C} 1$ is applied to larger entities such as a number of wells, a reservoir, or a field, these parameters are only empirical and are obtained by a curve-fitting process. Practically, this equation represents three different types of declines depending on the value of $b$; namely, an exponential decline for $b=0$, a hyperbolic decline for $b>0$ and $b<1$, and a harmonic decline for $b=1$. On the basis of the explanations above and for the sake of simplicity, in many of the industrial applications of evaluating reservoir oil production decline, the value of $b$ is often assumed to be zero, and, hence, equation $\mathrm{C} 1$ takes the form:

$$
q=q_{i} \exp \left(-D_{i} t\right)
$$


Equation $\mathrm{C} 2$ is rewritten in terms of cumulative oil production in the following form:

$$
Q=\frac{\left(q_{i}-q\right)}{D_{i}}
$$

where

$Q \quad$ is the cumulative oil production, in barrels.

These two equations, $\mathrm{C} 2$ and $\mathrm{C} 3$, were used for the analysis of oil production decline in this current study to determine the values of constants " $D_{i}$ " and " $q_{i}$ " in the above equations. For this purpose, these equations can be written as:

$$
\begin{gathered}
\ln (q)=\ln \left(q_{i}\right)-D_{i} t \\
q=q_{i}-D_{i} Q
\end{gathered}
$$

On the basis of equation $\mathrm{C} 4$, plotting the oil production rate $(q)$ versus production time $(t)$ on a semi-log graph will result in a straight line having an intercept equal to $\ln \left(q_{i}\right)$ and a slope equal to $D_{i}$. Alternatively, on the basis of equation C5, plotting the oil production rate $(q)$ versus cumulative oil production $(Q)$ will result in a straight line having an intercept and slope equal to $q_{i}$ and $D_{i}$, respectively. After values are determined for $D_{i}$ and $q_{i}$, equations $\mathrm{C} 4$ and $\mathrm{C} 5$ are used to predict the future oil production rate and the cumulative amount of recoverable oil, respectively. The current assessment methodology is designed to assess only the technically recoverable hydrocarbon for the carbon dioxide enhanced oil recovery $\left(\mathrm{CO}_{2}\right.$-EOR) application, implying no economic limit. If an economic evaluation is required in the future, first an appropriate economic hydrocarbon production rate $\left(q_{e c}\right)$ in reservoir barrels per day (bbl/day) needs to be defined below which hydrocarbon production from a given reservoir is considered to be uneconomic. The magnitude of the introduced value of $q_{e c}$ depends on each project configuration and specifications and external factors such as hydrocarbon prices that vary from one project to another. After the value of $q_{e c}$ is chosen, the field's productive life $\left(t_{e c}\right)$ and total economically recoverable hydrocarbon volume $\left(Q_{c c}\right)$ can be calculated by applying the following equations:

$$
\begin{gathered}
t_{e c}=-\frac{1}{D_{i}} \ln \left(\frac{q_{e c}}{q_{i}}\right) \\
Q_{e c}=-\frac{1}{D_{i}}\left(q_{i}-q_{e c}\right)
\end{gathered}
$$

For a technically recoverable hydrocarbon volume, designated as $Q_{\max }$, the recovery factor $(R F)$ under current production conditions is estimated from the following:

$$
R F=\frac{Q_{\max }}{O O I P} \times 100
$$

where

$Q_{\max }$ is the maximum cumulative oil production, in barrels (bbl);

OOIP is the original oil in place, in stock tank barrels (STB); and

$R F \quad$ is the recovery factor, expressed as a percentage.

If an incremental recovery factor is required for any phase (that is, primary, secondary, or tertiary), it is determined as the total calculated $R F$ at phase $i$ minus the total calculated $R F$ at the previous phase $(i-1)$ :

$$
R F_{\text {Incremental }}=R F_{i}-R F_{i-1}
$$

where

$i \quad$ is 1 for primary, 2 for secondary, and 3 for tertiary production.

For example, if the reservoir is currently under $\mathrm{CO}_{2}$-EOR, which was initiated after a waterflood, the calculated $R F$ at the current stage represents the total recovery, including all three stages of primary, waterflood, and $\mathrm{CO}_{2}$-EOR. Therefore, on the basis of equation $\mathrm{C} 9$, the additional recovery factor due to $\mathrm{CO}_{2}$-EOR is obtained by subtracting the calculated $R F$ values of the waterflood from the $R F$ value calculated for the $\mathrm{CO}_{2}$-EOR.

\section{Case Study}

The Oil and Gas Journal's 2012 survey of EOR projects (Koottungal, 2012; Kuuskraa, 2012) indicated that about $123 \mathrm{CO}_{2}$-EOR projects were active within the United States in 2012. Twenty-four fields (28 reservoirs) of these projects were initially selected for DCA. However, after the initial investigation, almost half of these projects were excluded from the DCA because they either did not develop long enough $\mathrm{CO}_{2}$-EOR decline periods appropriate for the DCA or were not in their decline phases yet. Data for the DCA were obtained from the comprehensive resource database (CRD), which was described by Carolus and others (in press); the CRD was developed from two proprietary databases by Nehring Associates Inc. (2012) and IHS Inc. (2012) and provided adequate injection and production data for only 12 fields containing 15 reservoirs. Therefore, the DCA was successfully applied 
only on these fields that have established a good $\mathrm{CO}_{2}$-EOR decline trend. The results of DCA on 15 reservoirs from these 12 fields are summarized in table $\mathrm{C} 1$ (tables follow the "References Cited"). The DCA for the Sable oil field in the west Texas section of the Permian Basin Province is presented here to show the procedure, and the details of the DCA for all the 15 reservoirs are provided in appendix C1. It is important to note that the Sable oil field was under a $\mathrm{CO}_{2}$-EOR operation from 1984 to 2001 and hence was not an active $\mathrm{CO}_{2}$-EOR project in 2012. However, because it makes a great example of the application of DCA, this field is being analyzed and presented herein.

In order to present the DCA procedure and demonstrate its applicability in modeling both waterflood and $\mathrm{CO}_{2}$-EOR decline periods for the Sable oil field, two figures were generated and are discussed. Figure $\mathrm{C} 1$ shows the semi-log plot of oil production rate versus production time for the Sable oil field. This graph shows that the oil production decline during waterflood that began in 1976 continued until 1984, when the $\mathrm{CO}_{2}$-EOR project was initiated. Because of $\mathrm{CO}_{2}$-EOR, the field production remained stable until 1993, when the production decline started again.

Figure $\mathrm{C} 2$ shows the oil production rate versus the cumulative oil production for the Sable oil field. As shown in the figure, the technically recoverable oil volume has increased from 9.85 million barrels (MMbbl) for the waterflood phase to 13.1 MMbbl for the $\mathrm{CO}_{2}$-EOR phase.
The oil production data for DCA are from IHS Inc. (2012), and the calculated OOIP values are from the CRD (Carolus and others, in press), which is based on data from the Nehring Associates Inc. database (2012) and IHS Inc. (2012). Because the OOIP values from the CRD are proprietary, the $O O I P$ values of reservoirs are reported qualitatively in table $\mathrm{C} 2$ and appendix $\mathrm{C} 1$ as small, medium, and large: a small $O O I P$ is less than or equal to $100 \mathrm{MMbbl}$, a medium $O O I P$ is between 100 and $1,000 \mathrm{MMbbl}$, and a large $O O I P$ is larger than or equal to 1,000 MMbbl. The OOIP of the San Andres Limestone of the Sable oil field was estimated volumetrically to be less than $100 \mathrm{MMbbl}$, thus classifying the reservoir in the Sable field as a small reservoir. By applying equation C8, the calculated recovery factors are 27.2 and 36.2 percent for waterflood and $\mathrm{CO}_{2}$-EOR, respectively (table $\mathrm{C} 2$ ). On the basis of equation $\mathrm{C} 9$, the additional recovery-factor value due to $\mathrm{CO}_{2}$-EOR is 9.0 percent. A similar process has been repeated for the selected 14 reservoirs located in Colorado, Wyoming, and the Permian Basin of Texas and New Mexico that were under $\mathrm{CO}_{2}$-EOR in 2012.

The additional recoverable oil volumes for $\mathrm{CO}_{2}$-EOR in 15 selected reservoirs were estimated by using DCA. Recovery factors were calculated by dividing the recoverable oil volumes at the end of the waterflood and at the end of $\mathrm{CO}_{2}$-EOR by the $O O I P$ of the individual reservoirs.

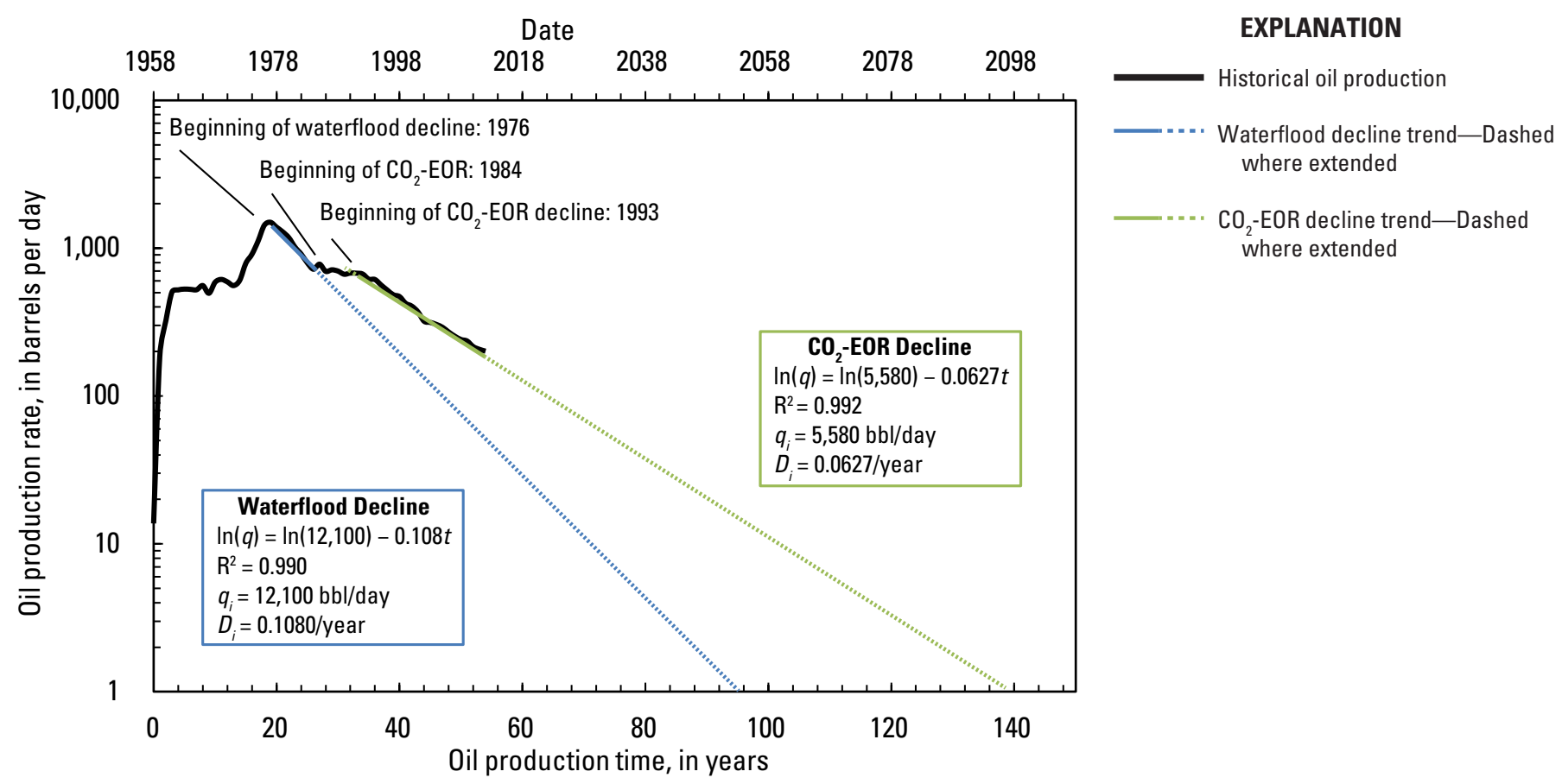

Figure C1. Semi-log plot of the oil production rate versus the oil production time for the San Andres Limestone in the Sable oil field in the west Texas section of the Permian Basin Province, showing the decline trends for both the waterflood and the carbon dioxide enhanced oil recovery $\left(\mathrm{CO}_{2}\right.$-EOR) phases. Data are from IHS Inc. (2012). Terms used in the decline equations on the graph: $D_{i}=$ initial decline rate per year; $q=$ oil production rate, in barrels per day $(\mathrm{bbl} / \mathrm{day}) ; q_{i}=$ initial oil production rate, in barrels per day (bbl/day); $\mathrm{R}^{2}=$ coefficient of determination; $t=$ oil production time, in years. 


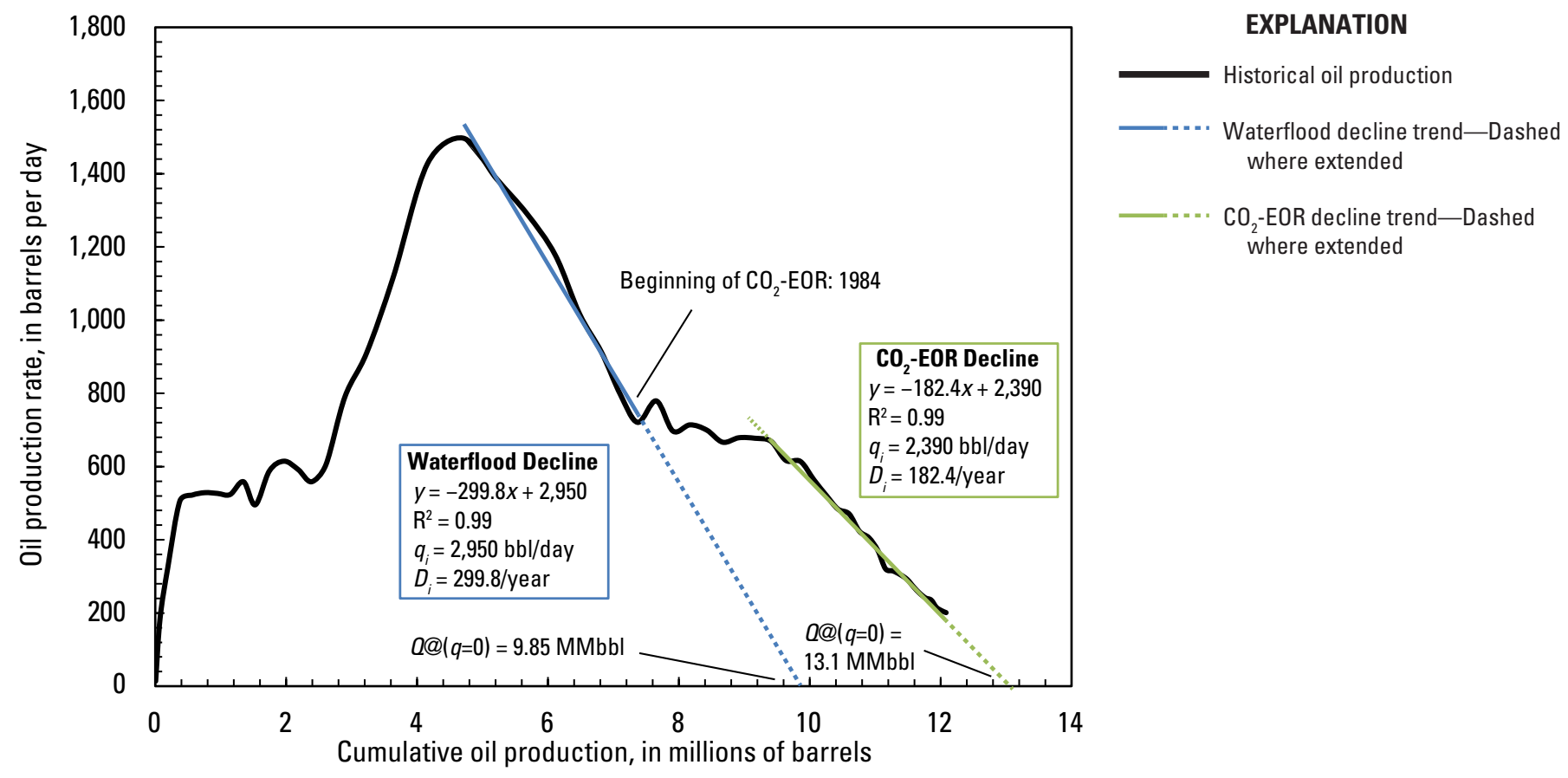

Figure C2. Graph of the oil production rate versus the cumulative oil production for the San Andres Limestone in the Sable oil field, Texas, showing the decline trends for both the waterflood and the carbon dioxide enhanced oil recovery $\left(\mathrm{CO}_{2}\right.$-EOR) phases. Data are from IHS Inc. (2012). Terms used in the decline equations on the graph: $D_{i}=$ initial decline rate per year; $q=$ oil production rate, in barrels per day (bbl/day); $q_{i}=$ initial oil production rate, in barrels per day (bbl/day); $Q=$ cumulative oil production, in millions of barrels (MMbbl); $\mathrm{R}^{2}=$ coefficient of determination; $x=$ cumulative oil production in the trendline equation, in millions of barrels; $y=$ oil production rate in the trendline equation, in barrels per day.

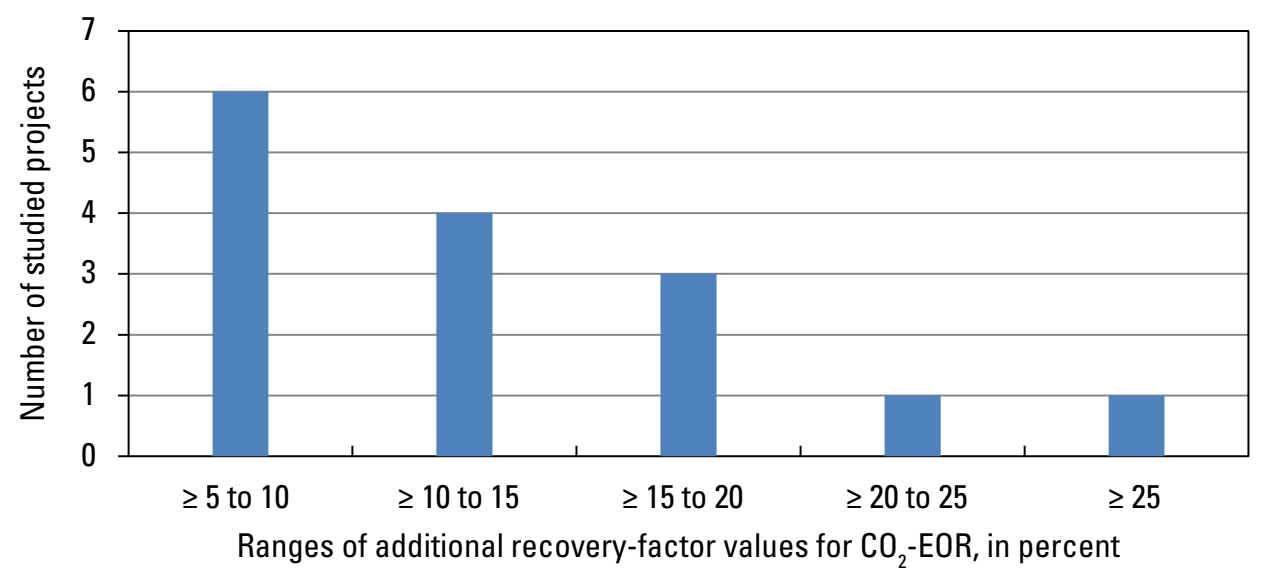

Figure C3. Bar graph showing the number of studied reservoirs having values of additional oil recovery factors due to carbon dioxide enhanced oil recovery $\left(\mathrm{CO}_{2}\right.$-EOR) in five different ranges. Recovery-factor values estimated by decline curve analysis are from table $\mathrm{C} 2$. 


\section{Discussion}

Generally speaking, the DCA is utilized in this study as a method that enables calculating both current and projected values of reservoir oil recovery-factor values at the end of a waterflood period and a subsequent $\mathrm{CO}_{2}$-EOR period. Table $\mathrm{C} 1$ summarizes the best match values of the initial oil production rate $\left(q_{i}\right)$ and the initial decline rate for oil production $\left(D_{i}\right)$ and the corresponding values of the coefficient of determination $\left(\mathrm{R}^{2}\right)$ values in the DCA equation for both waterflood and $\mathrm{CO}_{2}$-EOR decline periods of the studied reservoirs. As explained above, the $q_{i}$ and $D_{i}$ values are empirical matching parameters and do not carry any physical meanings. For comparison purposes, it can be observed from this table that the overall average values of $q_{i}$ and $D_{i}$ are $72,500 \mathrm{bbl} /$ day and $360.7 /$ year for the waterflood period and $125,400 \mathrm{bbls} /$ day and 190.5/year for the $\mathrm{CO}_{2}$-EOR period, respectively. It is important to note that the overall average values of $\mathrm{R}^{2}$ are 0.951 and 0.952 for the waterflood and $\mathrm{CO}_{2}$-EOR periods, respectively, indicating a good to excellent match for the waterflood and $\mathrm{CO}_{2}$-EOR periods. This observation highlights an important point that the basic DCA method as it has been routinely applied to model waterflood decline in performance analysis can also be utilized to model the $\mathrm{CO}_{2}$-EOR decline period with similar accuracy.

The calculated recovery factors for the technically recoverable oil volumes for the waterflood and $\mathrm{CO}_{2}$-EOR phases and the additional oil recovery for the $\mathrm{CO}_{2}$-EOR phase for all 15 studied reservoirs are reported in table $\mathrm{C} 2$. The results of this table indicate that the incremental oil recovery factor by $\mathrm{CO}_{2}$-EOR ranges from 6.6 percent for the Weber Sandstone in the Rangely field to 25.7 percent for the San Andres Limestone (dolomite) in the Wasson field, whereas the average overall calculated recovery factor for the studied reservoirs is 13.2 percent. The ranges of the additional recovery factor due to $\mathrm{CO}_{2}$-EOR from DCA along with the values from the review of literature on $\mathrm{CO}_{2}$-EOR in chapter $\mathrm{D}$ are utilized to substantiate the estimated values from the reservoir modeling as described in chapter B.

Data from table $\mathrm{C} 2$ reveal that the average additional recovery factor with $\mathrm{CO}_{2}$-EOR from the seven dolomite reservoirs producing from the San Andres Limestone is around 13.5 percent, whereas the other five carbonate reservoirs have an average additional recovery of 14.3 percent. The average additional recovery factor for the 3 clastic (sandstone) reservoirs is 10.9 percent, which is lower than the 13.8 percent for the 12 carbonate reservoirs. However, the data are limited in terms of samples and, therefore, it is hard to make any conclusive observations. In figure $\mathrm{C} 3$, the reservoirs that were evaluated for DCA are grouped according to their $R F$ values for $\mathrm{CO}_{2}$-EOR, and the graph shows that most of them are in the lower range ( 13 out of 15 are less than 20 percent) -6 are in the range of $\geq 5$ to 10 percent, 4 are in the range of $\geq 10$ to 15 percent, and 3 are in the range of $\geq 15$ to 20 percent.
From the lithology point of view, the majority of the studied reservoirs (12 out of 15) are carbonates and only 3 are sandstone reservoirs. This small sample size of sandstone reservoirs makes the comparison of the $\mathrm{CO}_{2}$-EOR performance in these two lithological classes practically impossible.

\section{References Cited}

Carolus, Marshall, Biglarbigi, Khosrow, Warwick, P.D., Attanasi, E.D., Freeman, P.A., and Lohr, C.D., in press, Overview of a comprehensive resource database for the assessment of recoverable hydrocarbons produced by carbon dioxide enhanced oil recovery: U.S. Geological Survey Techniques and Methods, book 7, chap. C16.

Fetkovich, M.J., 1980, Decline curve analysis using type curves: Journal of Petroleum Technology, v. 32, no. 6 (June 1980), p. 1065-1077, paper SPE-4629-PA.

Fetkovich, M.J., Vienot, M.E., Bradley, M.D., and Kiesow, U.G., 1987, Decline curve analysis using type curves - Case histories: SPE (Society of Petroleum Engineers) Formation Evaluation, v. 2, no. 4 (December 1987), p. 637-656, paper SPE-13169-PA.

Holm, L.W., and Josendal, V.A., 1974, Mechanisms of oil displacement by carbon dioxide: Journal of Petroleum Technology, v. 26, no. 12 (December 1974), p. 1427-1438, paper SPE-4736-PA.

IHS Inc., 2012, PIDM [Petroleum Information Data Model] relational U.S. well data [data current as of December 23, 2011]: Englewood, Colo., IHS Inc.

Koottungal, Leena, ed., 2012, 2012 worldwide EOR survey: Oil and Gas Journal, v. 110, no. 4 (April 2, 2012), p. 1-4, accessed in 2014 at http://www.ogj.com/articles/print/vol110/issue-4/general-interest/special-report-eor-heavy-oilsurvey/2012-worldwide-eor-survey.html.

Kuuskraa, Vello, 2012, QC updates carbon dioxide projects in OGJ's enhanced oil recovery survey: Oil and Gas Journal, v. 110, no. 7 (July 2, 2012), p. 1-4, accessed [in 2014] at http://www.ogj.com/articles/print/vol-110/issue-07/drillingproduction/qc-updates-carbon-dioxide-projects.html.

Nehring Associates Inc., 2012, Significant oil and gas fields of the United States database [data current as of December 2012]: Colorado Springs, Colo., Nehring Associates Inc. 
Table C1. Best match values of the initial oil production rate, the initial decline rate for oil production, and the corresponding coefficient of determination $\left(\mathrm{R}^{2}\right)$ values for both waterflood and carbon dioxide enhanced oil recovery $\left(\mathrm{CO}_{2}\right.$-EOR) decline periods of the studied reservoirs.

[The selection of the 15 studied reservoirs and the sources of data are described in chapter $\mathrm{C}$ of this report. Fourteen of the reservoirs had active $\mathrm{CO}_{2}$-EOR projects in 2012. The reservoir in the Sable oil field did not have an active $\mathrm{CO}_{2}$-EOR project in 2012, but it is included because it is a good example. The values in this table were determined by decline curve analysis. Each reservoir is described as a case study in appendix C1. State abbreviations: CO, Colorado; NM, New Mexico; TX, Texas; WY, Wyoming. Variables: $D_{i}$, initial decline rate per year in oil production; $q_{i}$, initial oil production rate, in barrels per day (bbl/day)]

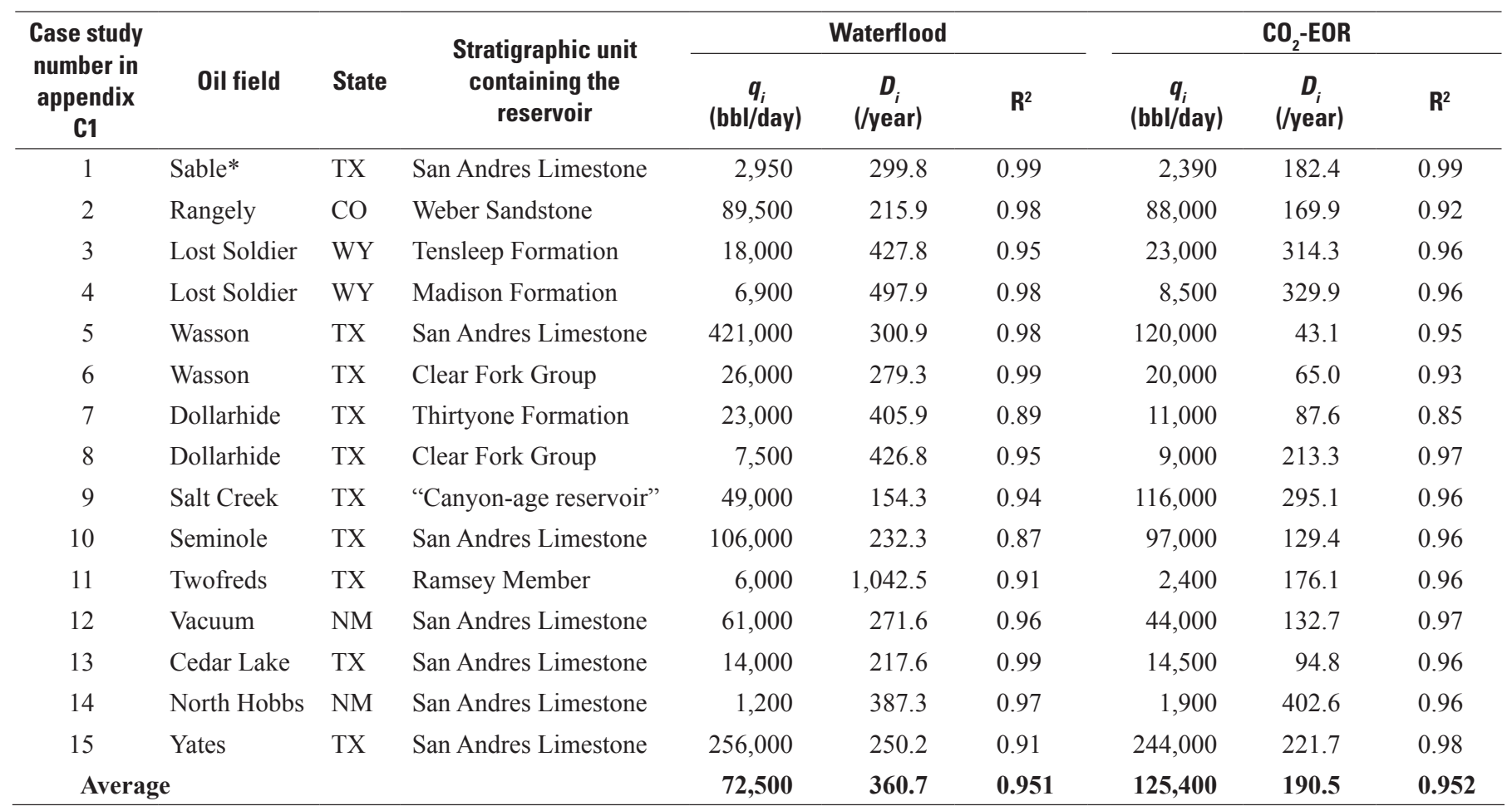

*The Sable oil field was under a $\mathrm{CO}_{2}$-EOR operation from 1984 to 2001 and hence is not included in the list of $\mathrm{CO}_{2}$-EOR projects that were active in 2012. Because it makes a great example of the application of decline curve analysis, this field is being analyzed and presented in chapter $\mathrm{C}$ and appendix $\mathrm{C} 1$ of this report. 
Table C2. Additional oil recovery factors estimated by using decline curve analysis for carbon dioxide enhanced oil recovery $\left(\mathrm{CO}_{2}\right.$-EOR) projects in 15 selected reservoirs.

[The selection of the 15 studied reservoirs and the sources of data are described in chapter $\mathrm{C}$ of this report. Each reservoir is described as a case study in appendix $\mathrm{C} 1$. Reservoirs are classified on the basis of the estimated original oil in place $(O O I P)$ as small, medium, or large; a small reservoir has less than or equal to100 million barrels (MMbbl) of OOIP, a medium reservoir has between 100 and 1,000 MMbbl of OOIP, and a large reservoir has more than or equal to 1,000 MMbbl of OOIP. State abbreviations: CO, Colorado; NM, New Mexico; TX, Texas; WY, Wyoming. Terms: $R F$, recovery factor; WF, waterflood; $\%$, percent]

\begin{tabular}{|c|c|c|c|c|c|c|c|c|}
\hline $\begin{array}{c}\text { Case study } \\
\text { number in } \\
\text { appendix } \\
\text { C1 }\end{array}$ & Oil field & State & $\begin{array}{l}\text { Stratigraphic unit } \\
\text { containing the } \\
\text { reservoir }\end{array}$ & Lithology & $\begin{array}{c}\text { Reservoir } \\
\text { size } \\
\text { classification }\end{array}$ & $\begin{array}{c}\boldsymbol{R} F \text { after WF } \\
(\%)^{*}\end{array}$ & $\begin{array}{c}R F \text { after } \\
\mathrm{CO}_{2} \text {-EOR } \\
(\%)^{*}\end{array}$ & $\begin{array}{c}\text { Additional } \\
R F \text { due to } \\
\mathrm{CO}_{2}-\mathrm{EOR} \\
(\%)\end{array}$ \\
\hline 1 & Sable** & $\mathrm{TX}$ & San Andres Limestone & Dolomite & Small & 27.2 & 36.2 & 9.0 \\
\hline 2 & Rangely & $\mathrm{CO}$ & Weber Sandstone & Sandstone & Large & 26.2 & 32.8 & 6.6 \\
\hline 3 & Lost Soldier & WY & Tensleep Formation & Sandstone & Medium & 17.7 & 30.0 & 12.3 \\
\hline 5 & Wasson & $\mathrm{TX}$ & San Andres Limestone & Dolomite & Large & 26.2 & 51.9 & 25.7 \\
\hline 6 & Wasson & $\mathrm{TX}$ & Clear Fork Group & Dolomite & Large & 9.3 & 30.0 & 20.7 \\
\hline 7 & Dollarhide & TX & Thirtyone Formation & Dolomite & Medium & 14.8 & 31.9 & 17.1 \\
\hline 8 & Dollarhide & TX & Clear Fork Group & Dolomite & Medium & 11.4 & 27.7 & 16.3 \\
\hline 12 & Vacuum & NM & San Andres Limestone & Dolomite & Large & 19.5 & 28.9 & 9.4 \\
\hline 13 & Cedar Lake & $\mathrm{TX}$ & San Andres Limestone & Dolomite & Medium & 19.5 & 27.9 & 8.4 \\
\hline 14 & North Hobbs & NM & San Andres Limestone & Dolomite & Small & 15.2 & 33.2 & 18.0 \\
\hline 15 & Yates & TX & San Andres Limestone & Dolomite & Large & 19.7 & 31.6 & 11.9 \\
\hline & \multicolumn{5}{|c|}{ Average for clastic (sandstone) reservoirs } & 18.8 & 29.7 & 10.9 \\
\hline & \multicolumn{5}{|c|}{ Average for carbonate (mostly dolomite) reservoirs } & $\mathbf{1 7 . 6}$ & 31.4 & 13.8 \\
\hline & \multicolumn{5}{|c|}{ Average for all 15 reservoirs } & 17.9 & 31.1 & 13.2 \\
\hline
\end{tabular}

The obtained recovery factors are based on the projection that both waterflood and $\mathrm{CO}_{2}$-EOR continue until oil production of zero ( $q=0$ barrels).

**The Sable oil field was under a $\mathrm{CO}_{2}$-EOR operation from 1984 to 2001 and hence is not included in the list of CO $-\mathrm{EOR}_{2}$ projects that were active in 2012. Because it makes a great example of the application of decline curve analysis, this field is being analyzed and presented in chapter $\mathrm{C}$ and appendix $\mathrm{C} 1$ of this report. 



\section{Appendix C1. Decline Curve Analysis of Selected Reservoirs}




\section{Appendix C1. Decline Curve Analysis of Selected Reservoirs}

The 15 reservoirs for case studies of decline curve analysis (DCA) were chosen because adequate geologic, reservoir, and production data were available for them. They all possess specific data on reservoir and fluid properties and vary significantly in terms of (1) size, as is obvious from their reported original oil in place (OOIP), (2) rock types, as they contain both clastic and carbonate reservoirs, (3) geographical locations, being distributed in different basins throughout Texas, New Mexico, Wyoming, and Colorado, and (4) source of carbon dioxide $\left(\mathrm{CO}_{2}\right)$, as they use both natural and industrial $\mathrm{CO}_{2}$. Miscible carbon dioxide enhanced oil recovery $\left(\mathrm{CO}_{2}\right.$-EOR) operations were used in 14 reservoirs, and an immiscible operation was used in 1 reservoir (case study 15). Fourteen of the reservoirs had active $\mathrm{CO}_{2}$-EOR projects in 2012. The reservoir in the Sable oil field (case study 1) did not have an active $\mathrm{CO}_{2}$-EOR project in 2012, but it is included because it is a good example. The 15 reservoirs all make great examples and case studies in demonstrating the applicability of DCA in predicting the behavior of decline periods for both waterflood and $\mathrm{CO}_{2}$-EOR phases.

The DCA was applied to the period of declining production of each reservoir separately, and the DCA parameters were obtained by curve fitting. The goodness of the obtained fit is presented by values for the coefficient of determination, $\mathrm{R}^{2}$, which are reported separately on the graph for each reservoir analyzed (figs. $\mathrm{C} 1-1$ to $\mathrm{C} 1-15)$. The closer the value of $\mathrm{R}^{2}$ is to 1 , the better the quality of the fit. The obtained DCA parameters were utilized to forecast the cumulative oil production when the oil production rates were available over the life of the reservoir for both waterflood and $\mathrm{CO}_{2}$-EOR phases; for this study, the economic hydrocarbon production rate $\left(q_{e c}\right)$ is assumed to be 0 reservoir barrels per day. This process also made it possible to estimate the reservoir's additional oil recovery due to the $\mathrm{CO}_{2}$-EOR operation that was modeled.

It is important to note that this study does not present the technical and operational details of reservoirs described in the case studies. Nor does it provide a detailed insight into the extent of the $\mathrm{CO}_{2}$-EOR operation for each investigated project.

\section{Case Study 1. San Andres Limestone, Sable Oil Field}

The San Andres Limestone in the Sable oil field in Texas is an oil-bearing dolomite formation that was under $\mathrm{CO}_{2}$-EOR operation between 1984 and 2001. On the basis of its OOIP, the San Andres Limestone in this field is considered a relatively small oil reservoir. The production decline under waterflood started in 1976 and continued until 1984 when the $\mathrm{CO}_{2}$-EOR operation was initiated in various sections of the reservoir. As a result of the $\mathrm{CO}_{2}$-EOR, the field's oil production rate remained stable over the course of 9 years until 1993, when the oil production began to decline again. The details of both waterflood and $\mathrm{CO}_{2}$-EOR declines and the relevant DCA equations and parameters are presented in figure $\mathrm{C} 1-1$.

\section{Case Study 2. Weber Sandstone, Rangely Oil Field}

The Weber Sandstone in the Rangely oil field in Colorado is an oil-bearing sandstone formation that was under $\mathrm{CO}_{2}$-EOR operations in 2012. On the basis of its OOIP, the Weber Sandstone in this field is classified as a large oil reservoir. The waterflood decline of the field started in 1978 and continued until 1986, when the $\mathrm{CO}_{2}$-EOR operation started in various sections of the reservoir. As a result of the $\mathrm{CO}_{2}$-EOR, the field's oil production rate increased approximately 10 percent over the course of 5 years until 1991, when the decline in production started again. This reservoir was among the largest clastic reservoirs undergoing $\mathrm{CO}_{2}$-EOR in 2012. The details of both waterflood and $\mathrm{CO}_{2}$-EOR declines and the obtained relevant DCA equations and parameters are presented in figure $\mathrm{C} 1-2$.

\section{Case Study 3. Tensleep Formation, Lost Soldier Oil Field}

The Tensleep Formation in the Lost Soldier oil field in Wyoming is an oil-bearing sandstone formation that was under $\mathrm{CO}_{2}$-EOR operations in 2012. On the basis of its OOIP, the Tensleep Formation in this field is classified as a mediumsized oil reservoir. The waterflood decline of the field started in 1978 and continued until 1988, when the $\mathrm{CO}_{2}$-EOR operation started in various sections of the reservoir. As a result of the $\mathrm{CO}_{2}$-EOR, the field's oil production rate increased approximately 300 percent over the course of 3 years until 1991, when the decline in production started again. The production profile of this reservoir shows two distinct and classical declines for both waterflood and $\mathrm{CO}_{2}$-EOR periods. The details of both waterflood and $\mathrm{CO}_{2}$-EOR declines and the obtained relevant DCA equations and parameters are presented in figure $\mathrm{C} 1-3$.

\section{Case Study 4. Madison Formation, Lost Soldier Oil Field}

The Madison Formation in the Lost Soldier oil field in Wyoming is an oil-bearing carbonate (limestone-dolomite) formation that was under $\mathrm{CO}_{2}$-EOR operations in 2012. On the basis of its OOIP, the Madison Formation in this field is classified as a medium-sized oil reservoir. The waterflood decline of the field started in 1984 and continued until 1989, when the $\mathrm{CO}_{2}$-EOR operation started in various sections of the reservoir. As a result of the $\mathrm{CO}_{2}$-EOR, the field's oil production rate increased approximately 40 percent over the course of 16 
years until 2005, when the decline in production started again. The production profile of this reservoir shows two distinct and classical declines for both waterflood and $\mathrm{CO}_{2}$-EOR periods. The details of both waterflood and $\mathrm{CO}_{2}$-EOR declines and the obtained relevant DCA equations and parameters are presented in figure $\mathrm{C} 1-4$.

\section{Case Study 5. San Andres Limestone, Wasson Oil Field}

The San Andres Limestone in the Wasson oil field in the Permian Basin in Texas is an oil-bearing carbonate (dolomite) formation that was under $\mathrm{CO}_{2}$-EOR operations in 2012. On the basis of its OOIP, the San Andres Limestone in this field is classified as a large oil reservoir. The waterflood decline of the field started in 1975 and continued until 1983, when the $\mathrm{CO}_{2}$-EOR operation started in various sections of the reservoir. As a result of the $\mathrm{CO}_{2}$-EOR, the field's oil production decline rate has decreased since. The San Andres Limestone in the Wasson field is one of the largest carbonate reservoirs undergoing $\mathrm{CO}_{2}$-EOR worldwide. The details of both waterflood and $\mathrm{CO}_{2}$-EOR declines and the obtained relevant DCA equations and parameters are presented in figure $\mathrm{C} 1-5$.

\section{Case Study 6. Clear Fork Group, Wasson Oil Field}

The Clear Fork Group in the Wasson oil field in the Permian Basin in Texas is an oil-bearing carbonate (dolomite) formation that was under $\mathrm{CO}_{2}$-EOR operations in 2012. On the basis of its OOIP, the Clear Fork Group in this field is classified as a large oil reservoir. The waterflood decline of the field started in 1968 and continued until 1984, when the $\mathrm{CO}_{2}$-EOR operation started in various sections of the reservoir. As a result of the $\mathrm{CO}_{2}$-EOR, the field's oil production rate increased approximately 93 percent over the course of 13 years until 1997, when it started to decline again. The details of both waterflood and $\mathrm{CO}_{2}$-EOR declines and the obtained relevant DCA equations and parameters are presented in figure $\mathrm{C} 1-6$.

\section{Case Study 7. Thirtyone Formation, Dollarhide Oil Field}

The Thirtyone Formation in the Dollarhide oil field in the Permian Basin in Texas is an oil-bearing chert and carbonate (dolomite) formation that was under $\mathrm{CO}_{2}$-EOR operations in 2012. On the basis of its OOIP, the Thirtyone Formation in this field is classified as a medium-sized oil reservoir. The waterflood decline of the field started in 1965 and continued until 1985 , when the $\mathrm{CO}_{2}$-EOR operation started in various sections of the reservoir. As a result of the $\mathrm{CO}_{2}$-EOR, the field's oil production rate increased approximately 118 percent over the course of 13 years until 1998, when it started to decline again. This reservoir is one of the best examples to demonstrate clearly the effect of $\mathrm{CO}_{2}$-EOR on a reservoir's oil production rate and cumulative production. The details of both waterflood and $\mathrm{CO}_{2}$-EOR declines and the obtained relevant DCA equations and parameters are presented in figure $\mathrm{C} 1-7$.

\section{Case Study 8. Clear Fork Group, Dollarhide Oil Field}

The Clear Fork Group in the Dollarhide oil field in the Permian Basin in Texas is an oil-bearing carbonate (dolomite) formation that was under $\mathrm{CO}_{2}$-EOR operations in 2012. On the basis of its OOIP, the Clear Fork Group in this field is classified as a medium-sized oil reservoir. The waterflood decline of the field started in 1970 and continued until 1977. On the basis of the available production data, it is not possible to investigate what happened between 1977 and 1995, during which time the reservoir oil production rate stopped declining and increased slightly. This change in the oil production decline could be due to infill drilling and (or) changes in the waterflood scheme in different sections of the reservoir. In November 1995, the $\mathrm{CO}_{2}$-EOR operation started in this reservoir. As a result of the $\mathrm{CO}_{2}$-EOR, the field's oil production rate increased approximately 139 percent over the course of 4 years until 1999, when it started to decline again. The details of both waterflood and $\mathrm{CO}_{2}$-EOR declines and the obtained relevant DCA equations and parameters are presented in figure $\mathrm{C} 1-8$.

\section{Case Study 9. "Canyon-age reservoir," Salt Creek Oil Field}

The "Canyon-age reservoir" in the Salt Creek oil field in the Permian Basin in Texas is an oil-bearing carbonate (limestone) formation that was under $\mathrm{CO}_{2}$-EOR operations in 2012. On the basis of its OOIP, the "Canyon-age reservoir" in this field is classified as a large oil reservoir. The waterflood decline of the field started in 1972 and continued until 1993, when the $\mathrm{CO}_{2}$-EOR operation started in various sections of the reservoir. As a result of the $\mathrm{CO}_{2}$-EOR, the field's oil production rate increased approximately 38 percent over the course of 4 years until 1997, when it started to decline again. The details of both waterflood and $\mathrm{CO}_{2}$-EOR declines and the obtained relevant DCA equations and parameters are presented in figure $\mathrm{C} 1-9$.

\section{Case Study 10. San Andres Limestone, Seminole Oil Field}

The San Andres Limestone in the Seminole oil field in the Permian Basin in Texas is an oil-bearing carbonate (dolomite) formation that was under $\mathrm{CO}_{2}$-EOR operations in 2012. On the basis of its OOIP, the San Andres Limestone in this field is classified as a large oil reservoir. The waterflood decline of the field started in 1977 and continued until 1983, when the $\mathrm{CO}_{2}$-EOR operation started in various sections of the reservoir. 
As a result of the $\mathrm{CO}_{2}$-EOR, the field's oil production rate increased approximately 37 percent over the course of 8 years until 1991, when it started to decline again. The details of both waterflood and $\mathrm{CO}_{2}$-EOR declines and the obtained relevant DCA equations and parameters are presented in figure $\mathrm{C} 1-10$.

\section{Case Study 11. Ramsey Member, Twofreds Oil Field}

The Ramsey Member of the Bell Canyon Formation in the Twofreds oil field in the Permian Basin in Texas contains an oil-bearing sandstone that was under $\mathrm{CO}_{2}$-EOR operations in 2012. On the basis of its OOIP, the sandstone of the Ramsey Member in this field is classified as a small oil reservoir. The waterflood decline of the field started in 1967 and continued until 1974, when the $\mathrm{CO}_{2}$-EOR operation started in various sections of the reservoir. As a result of the $\mathrm{CO}_{2}$-EOR, the field's oil production rate increased approximately 323 percent over the course of 11 years until 1985, when it started to decline again. The details of both waterflood and $\mathrm{CO}_{2}$-EOR declines and the obtained relevant DCA equations and parameters are presented in figure $\mathrm{C} 1-11$.

\section{Case Study 12. San Andres Limestone, Vacuum Oil Field}

The San Andres Limestone in the Vacuum oil field in the Permian Basin in New Mexico is an oil-bearing carbonate (dolomite) formation that was under $\mathrm{CO}_{2}$-EOR operations in 2012. On the basis of its OOIP, the San Andres Limestone in this field is classified as a large oil reservoir. The waterflood decline of the field started in 1983 and continued until 1997, when the $\mathrm{CO}_{2}$-EOR operation started in various sections of the reservoir. As a result of the $\mathrm{CO}_{2}$-EOR, the field's oil production rate stayed stable until 2001, when it started to decline again. The details of both waterflood and $\mathrm{CO}_{2}$-EOR declines and the obtained relevant DCA equations and parameters are presented in figure $\mathrm{C} 1-12$.

\section{Case Study 13. San Andres Limestone, Cedar Lake Oil Field}

The San Andres Limestone in the Cedar Lake oil field in the Permian Basin in Texas is an oil-bearing carbonate (dolomite) formation that was under $\mathrm{CO}_{2}$-EOR operations in 2012. On the basis of its OOIP, the San Andres Limestone in this field is classified as a medium-sized oil reservoir. The waterflood decline of the field started in 1983 and continued until 1994 , when the $\mathrm{CO}_{2}$-EOR operation started in various sections of the reservoir. As a result of the $\mathrm{CO}_{2}$-EOR, the field's oil production rate increased approximately 25 percent over the course of 7 years until 2001, when it started to decline again.
The details of both waterflood and $\mathrm{CO}_{2}$-EOR declines and the obtained relevant DCA equations and parameters are presented in figure $\mathrm{C} 1-13$.

\section{Case Study 14. San Andres Limestone, North Hobbs Oil Field}

The San Andres Limestone in the North Hobbs oil field in the Permian Basin in New Mexico is an oil-bearing carbonate (dolomite) formation that was under $\mathrm{CO}_{2}$-EOR operations in 2012. On the basis of its OOIP, the San Andres Limestone in this field is classified as a small oil reservoir. The waterflood decline of the field started in 2000 and continued until 2003 , when the $\mathrm{CO}_{2}$-EOR operation started in various sections of the reservoir. As a result of the $\mathrm{CO}_{2}$-EOR, the field's oil production rate increased approximately 104 percent over the course of 3 years until 2006, when it started to decline again. The details of both waterflood and $\mathrm{CO}_{2}$-EOR declines and the obtained relevant DCA equations and parameters are presented in figure $\mathrm{C} 1-14$.

\section{Case Study 15. San Andres Limestone, Yates Oil Field}

The San Andres Limestone in the Yates oil field in the Permian Basin in Texas is an oil-bearing carbonate (dolomite) formation that was under $\mathrm{CO}_{2}$-EOR operations in 2012. It should be noted that unlike the previous examples, the $\mathrm{CO}_{2}$-EOR operation in this field is immiscible. On the basis of its OOIP, the San Andres Limestone in this field is classified as a large oil reservoir. The waterflood decline of the field started in 2000 and continued until 2004, when the $\mathrm{CO}_{2}$-EOR operation started in various sections of the reservoir. As a result of the $\mathrm{CO}_{2}$-EOR, the field's oil production rate increased approximately 48 percent over the course of 2 years until 2006, when it started to decline again. The details of both waterflood and $\mathrm{CO}_{2}$-EOR declines and the obtained relevant DCA equations and parameters are presented in figure $\mathrm{C} 1-15$.

\section{Reference Cited}

IHS Inc., 2012, PIDM [Petroleum Information Data Model] relational U.S. well data [data current as of December 23, 2011]: Englewood, Colo., IHS Inc. 


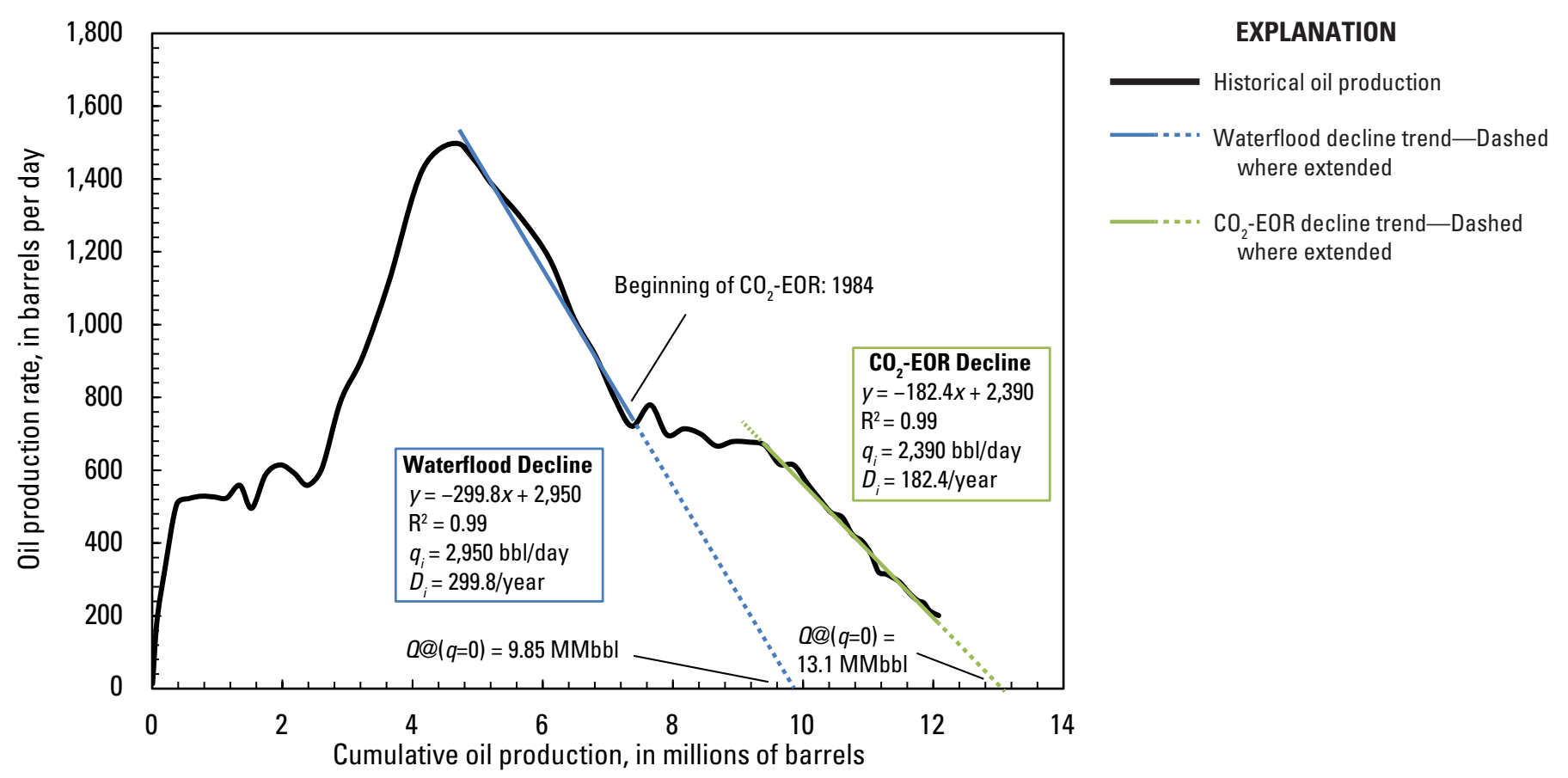

Figure C1-1. Graph of the oil production rate versus the cumulative oil production for the San Andres Limestone in the Sable oil field, Texas, showing the decline trends for both the waterflood and the carbon dioxide enhanced oil recovery $\left(\mathrm{CO}_{2}-\mathrm{EOR}\right)$ phases. Data are from IHS Inc. (2012). Terms used in the decline equations on the graph: $D_{i}=$ initial decline rate per year; $q=$ oil production rate, in barrels per day (bbl/day); $q_{i}=$ initial oil production rate, in barrels per day (bbl/day); $Q=$ cumulative oil production, in millions of barrels (MMbbl); $\mathrm{R}^{2}=$ coefficient of determination; $x=$ cumulative oil production in the trendline equation, in millions of barrels; $y=$ oil production rate in the trendline equation, in barrels per day. 


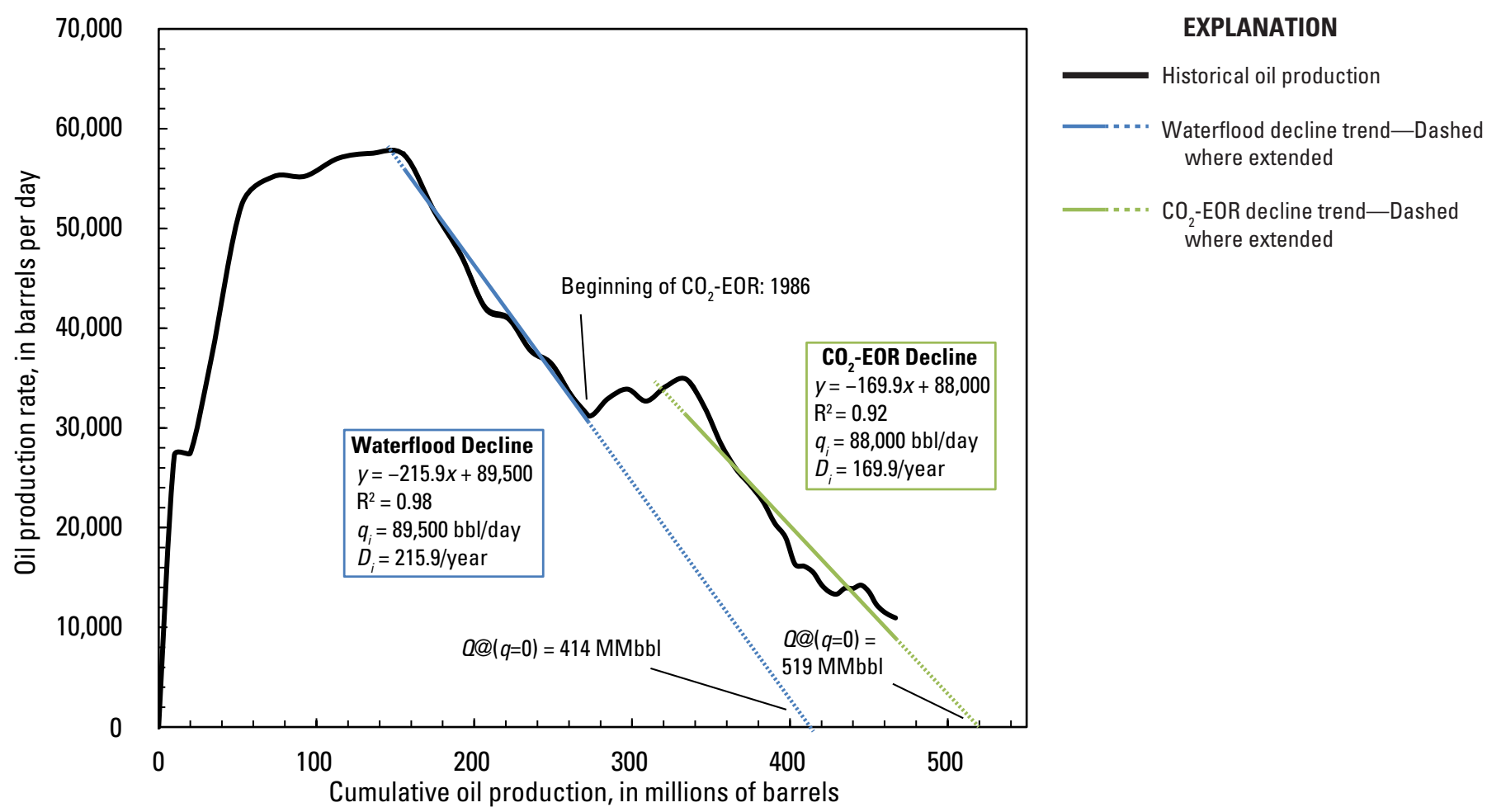

Figure C1-2. Graph of the oil production rate versus the cumulative oil production for the Weber Sandstone in the Rangely oil field, Colorado, showing the decline trends for both the waterflood and the carbon dioxide enhanced oil recovery $\left(\mathrm{CO}_{2}\right.$-EOR) phases. Data are from IHS Inc. (2012). Terms are as defined for figure C1-1. For completeness, this figure is included in the appendix even though it is also shown as text-figure $\mathrm{C} 2$.

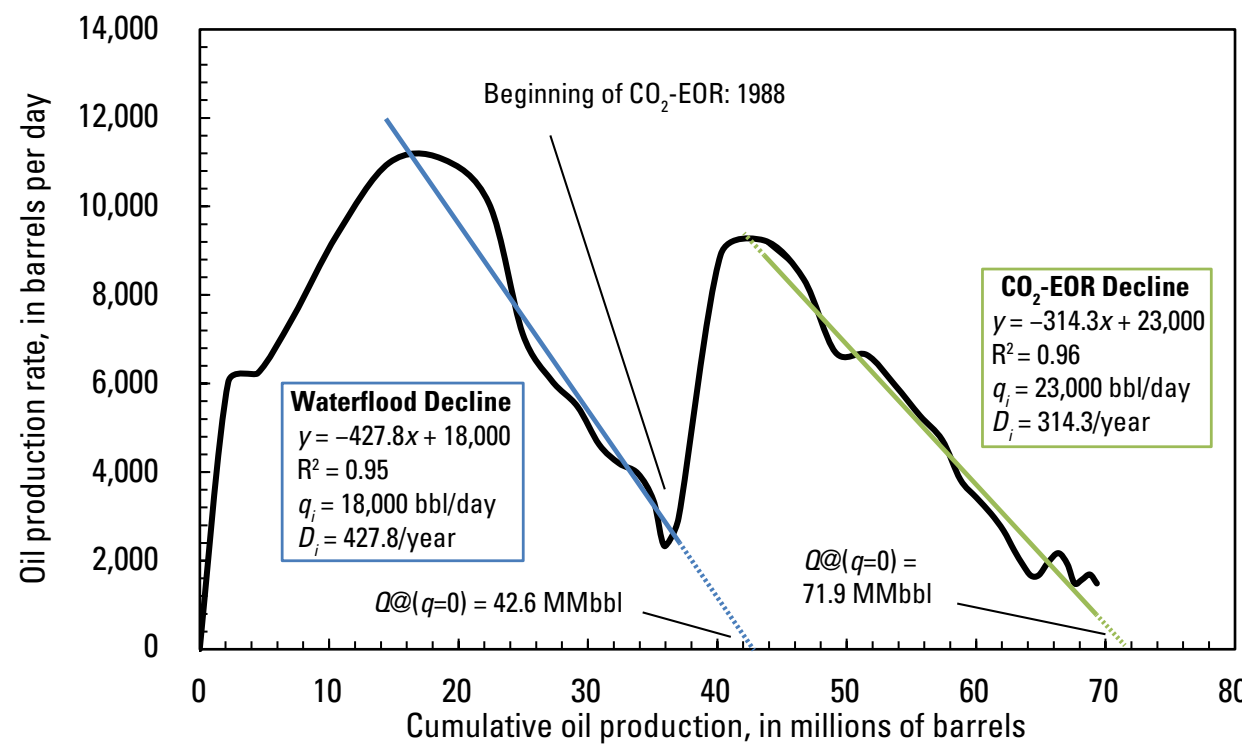

\section{EXPLANATION}



西

Figure C1-3. Graph of the oil production rate versus the cumulative oil production for the Tensleep Formation in the Lost Soldier oil field, Wyoming, showing the decline trends for both the waterflood and the carbon dioxide enhanced oil recovery ( $\mathrm{CO}_{2}$-EOR) phases. Data are from IHS Inc. (2012). Terms are as defined for figure C1-1. 




Figure C1-4. Graph of the oil production rate versus the cumulative oil production for the Madison Formation in the Lost Soldier oil field, Wyoming, showing the decline trends for both the waterflood and the carbon dioxide enhanced oil recovery ( $\mathrm{CO}_{2}$-EOR) phases. Data are from IHS Inc. (2012). Terms are as defined for figure C1-1.



Figure C1-5. Graph of the oil production rate versus the cumulative oil production for the San Andres Limestone in the Wasson oil field, Texas, showing the decline trends for both the waterflood and the carbon dioxide enhanced oil recovery $\left(\mathrm{CO}_{2}\right.$-EOR) phases. Data are from IHS Inc. (2012). Terms are as defined for figure C1-1. 


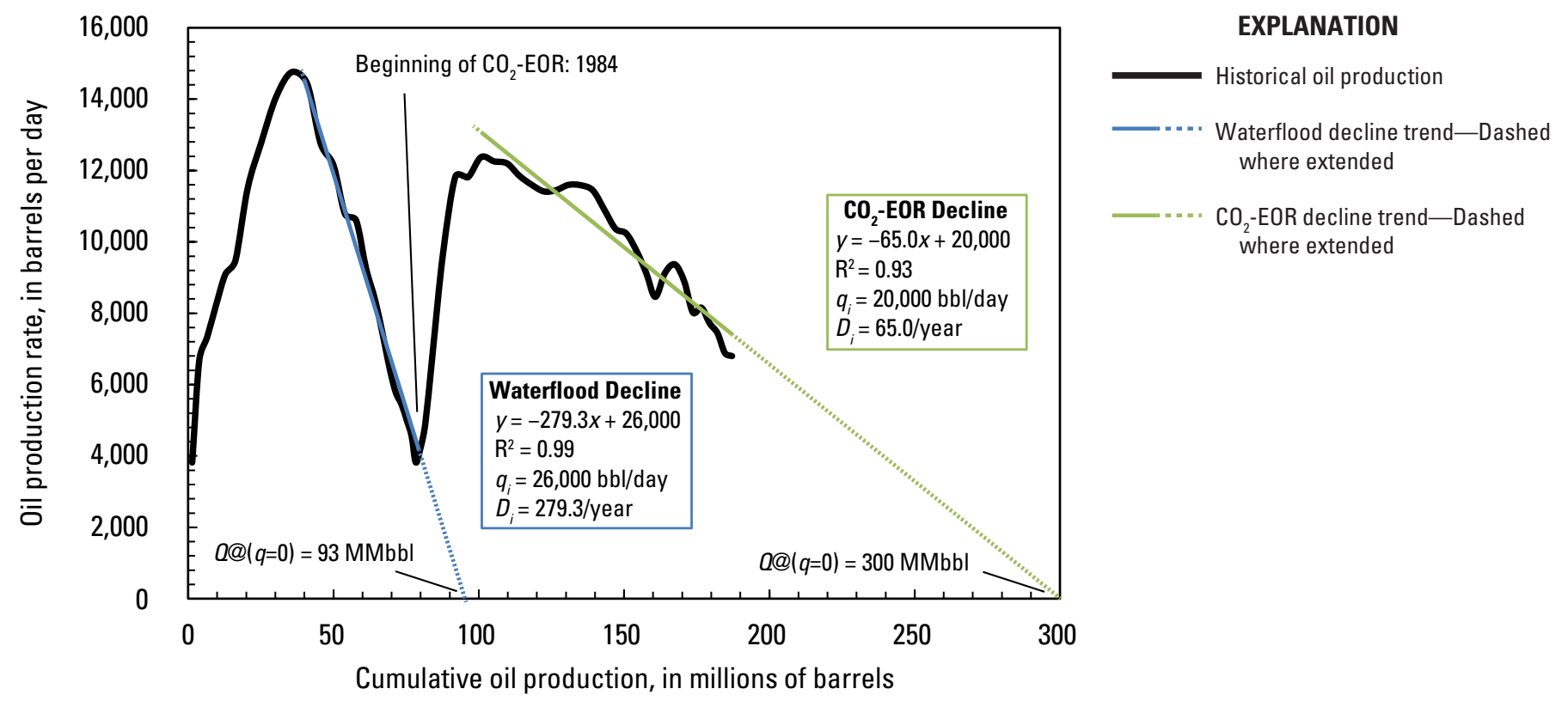

Figure C1-6. Graph of the oil production rate versus the cumulative oil production for the Clear Fork Group in the Wasson oil field, Texas, showing the decline trends for both the waterflood and the carbon dioxide enhanced oil recovery $\left(\mathrm{CO}_{2}-\mathrm{EOR}\right)$ phases. Data are from IHS Inc. (2012). Terms are as defined for figure C1-1.



Figure C1-7. Graph of the oil production rate versus the cumulative oil production for the Thirtyone Formation in the Dollarhide oil field, Texas, showing the decline trends for both the waterflood and the carbon dioxide enhanced oil recovery $\left(\mathrm{CO}_{2}-\mathrm{EOR}\right)$ phases. Data are from IHS Inc. (2012). Terms are as defined for figure C1-1. 


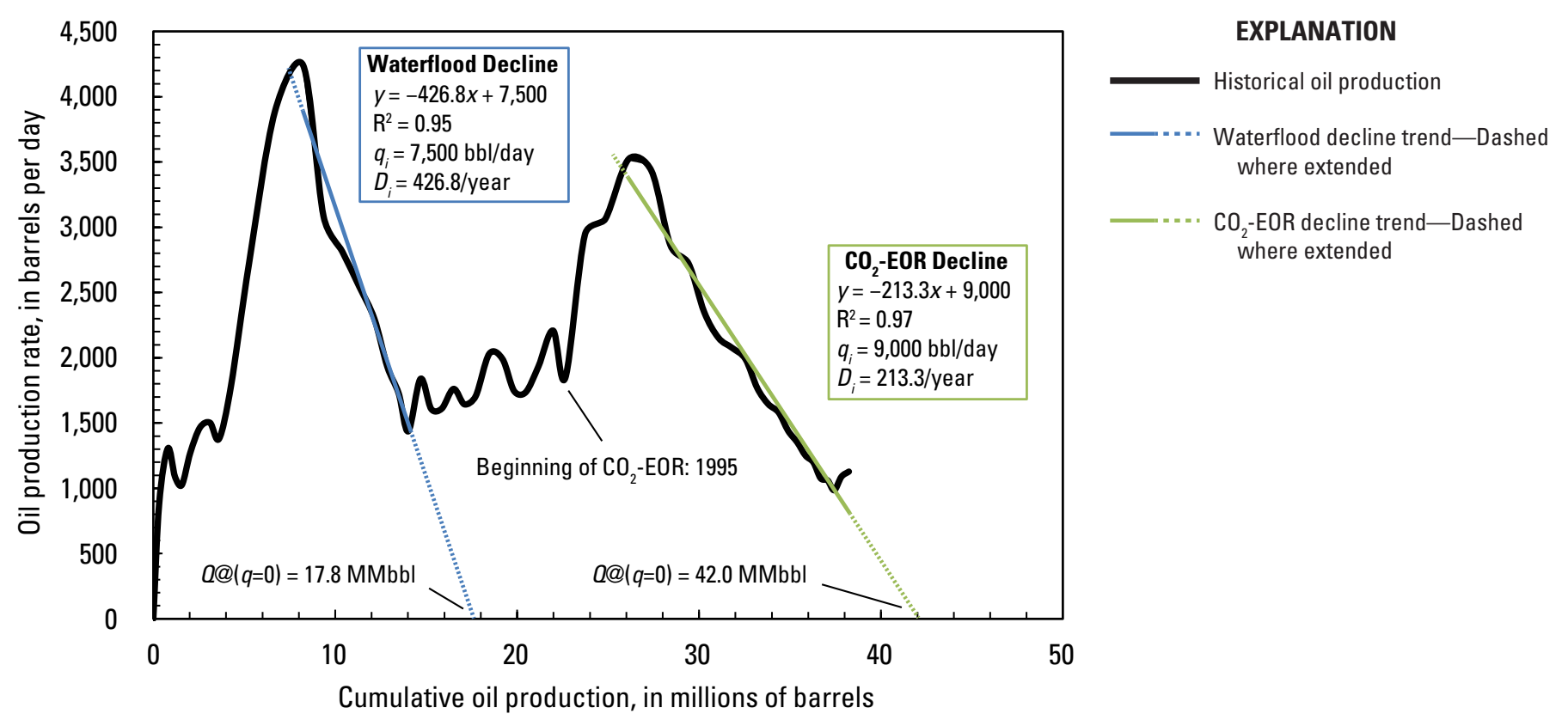

Figure C1-8. Graph of the oil production rate versus the cumulative oil production for the Clear Fork Group in the Dollarhide oil field, Texas, showing the decline trends for both the waterflood and the carbon dioxide enhanced oil recovery $\left(\mathrm{CO}_{2}-\mathrm{EOR}\right)$ phases. Data are from IHS Inc. (2012). Terms are as defined for figure C1-1.



Figure C1-9. Graph of the oil production rate versus the cumulative oil production for the "Canyon-age reservoir" in the Salt Creek oil field, Texas, showing the decline trends for both the waterflood and the carbon dioxide enhanced oil recovery $\left(\mathrm{CO}_{2}\right.$-EOR) phases. Data are from IHS Inc. (2012). Terms are as defined for figure C1-1. 


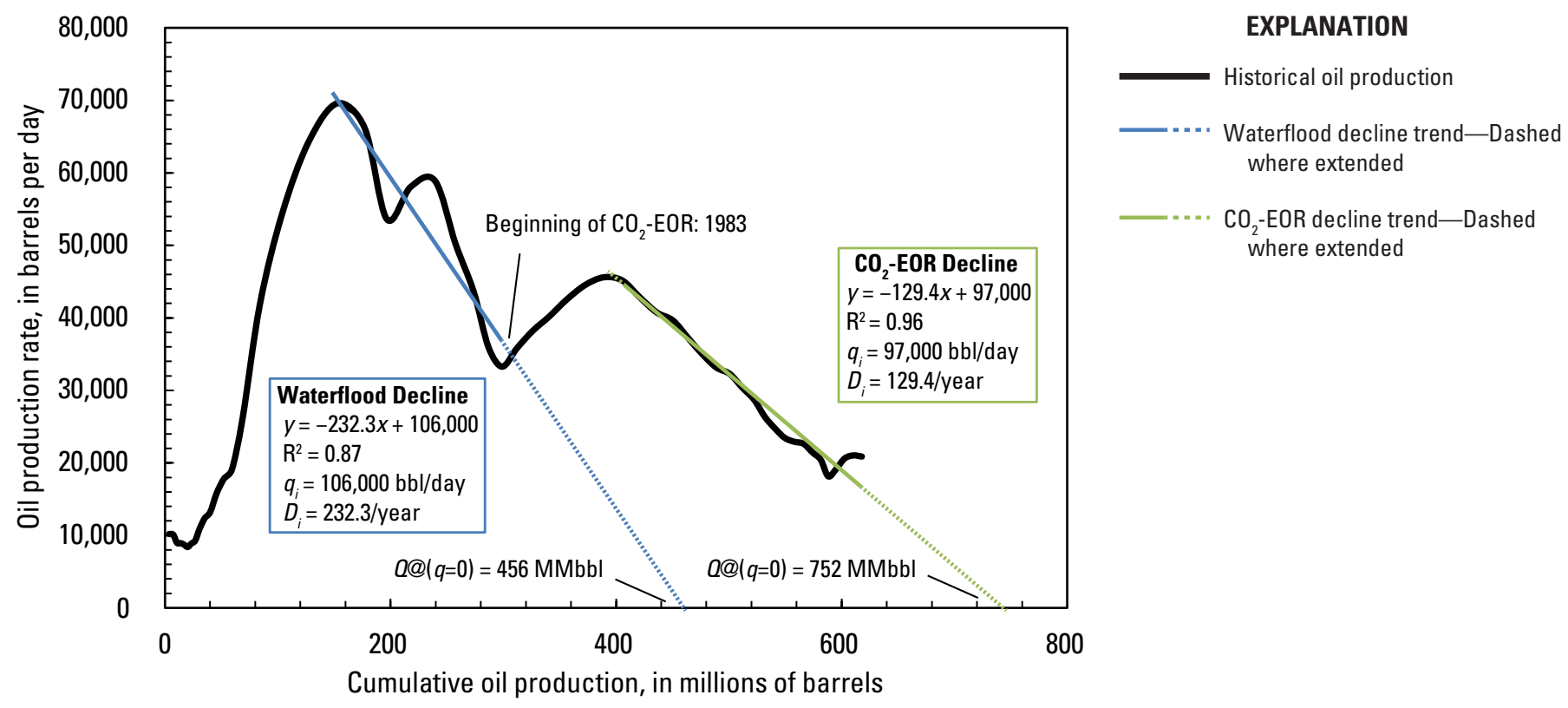

Figure C1-10. Graph of the oil production rate versus the cumulative oil production for the San Andres Limestone in the Seminole oil field, Texas, showing the decline trends for both the waterflood and the carbon dioxide enhanced oil recovery $\left(\mathrm{CO}_{2}\right.$-EOR) phases. Data are from IHS Inc. (2012). Terms are as defined for figure C1-1.

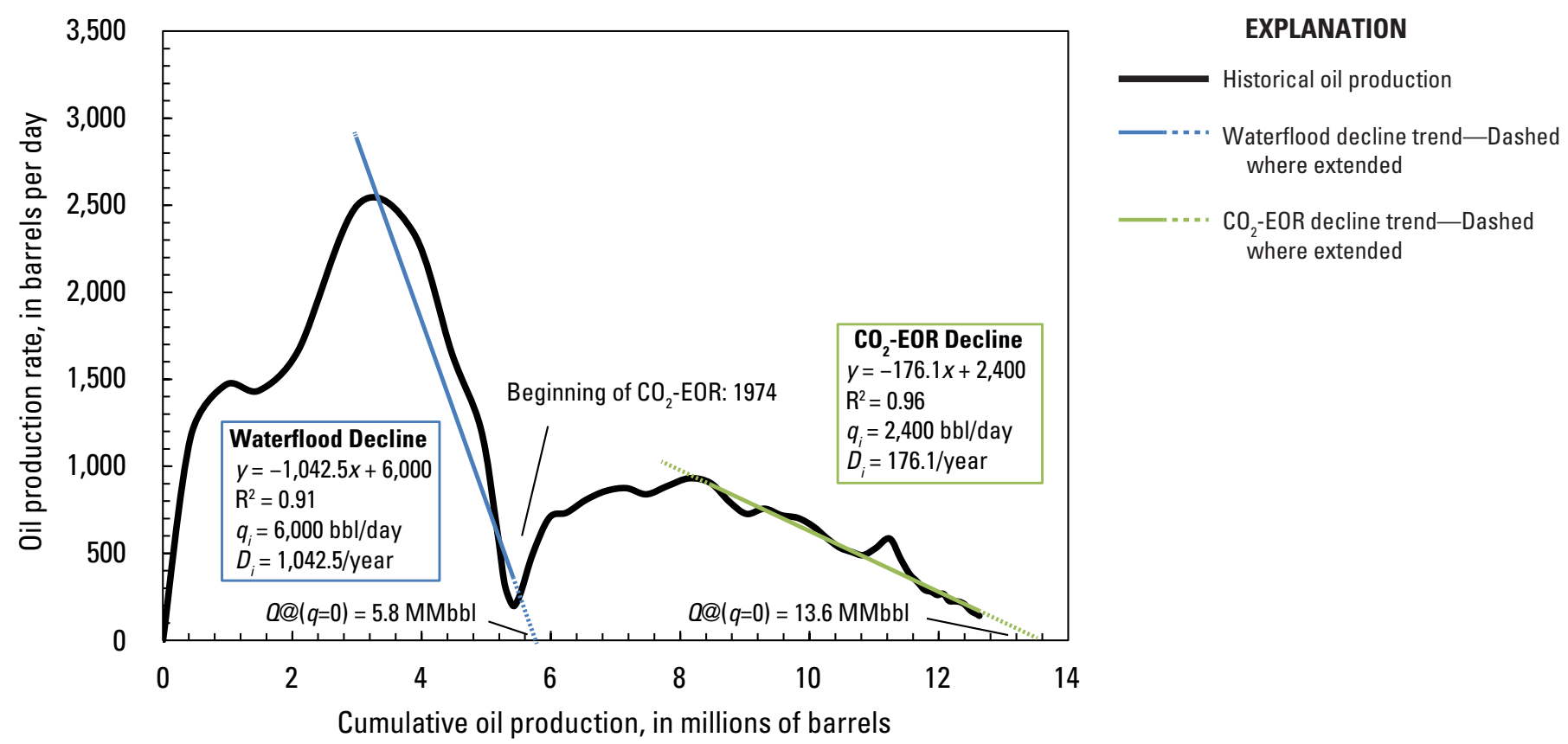

Figure C1-11. Graph of the oil production rate versus the cumulative oil production for the sandstone of the Ramsey Member of the Bell Canyon Formation in the Twofreds oil field, Texas, showing the decline trends for both the waterflood and the carbon dioxide enhanced oil recovery $\left(\mathrm{CO}_{2}-\mathrm{EOR}\right)$ phases. Data are from IHS Inc. (2012). Terms are as defined for figure $\mathrm{C1}-1$. 


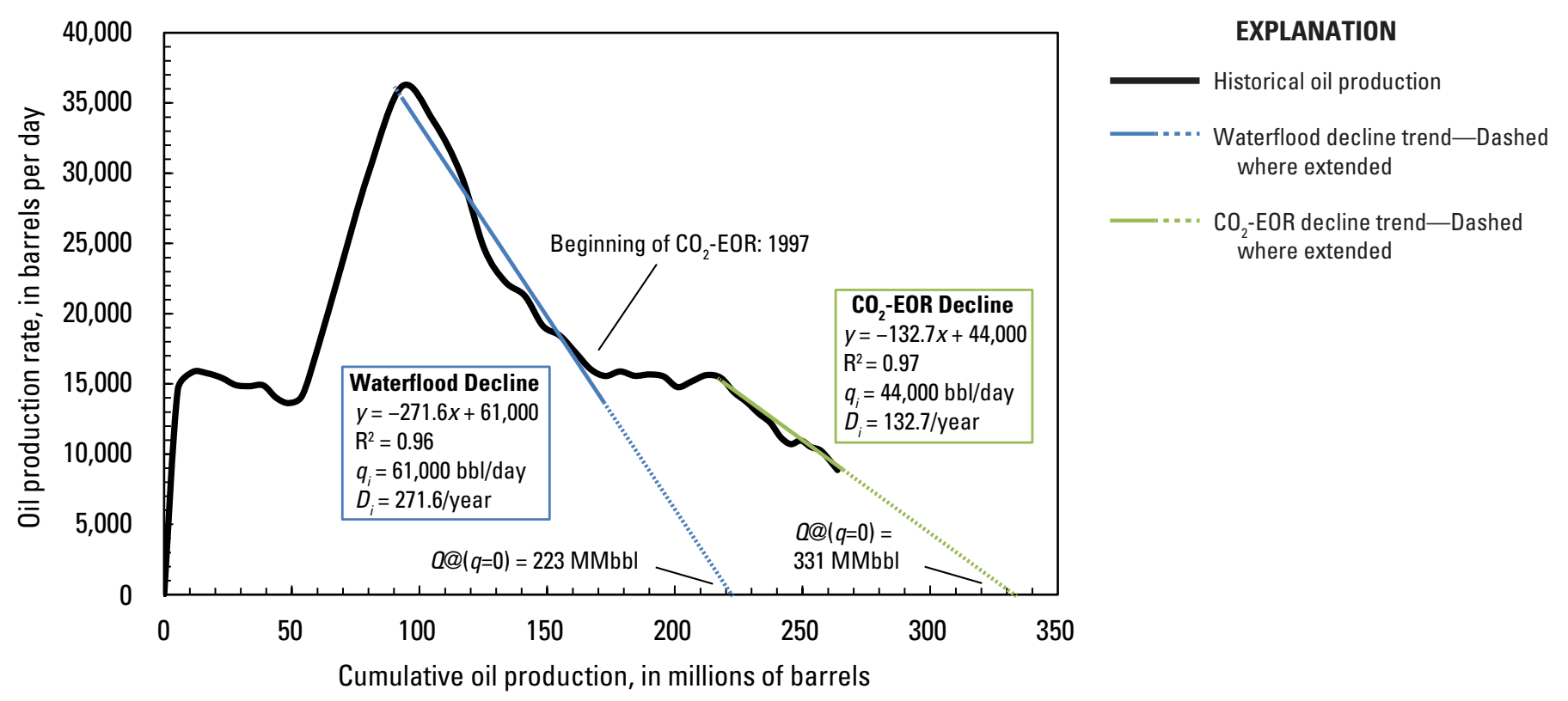

Figure C1-12. Graph of the oil production rate versus the cumulative oil production for the San Andres Limestone in the Vacuum oil field, New Mexico, showing the decline trends for both the waterflood and the carbon dioxide enhanced oil recovery ( $\mathrm{CO}_{2}$-EOR) phases. Data are from IHS Inc. (2012). Terms are as defined for figure C1-1.

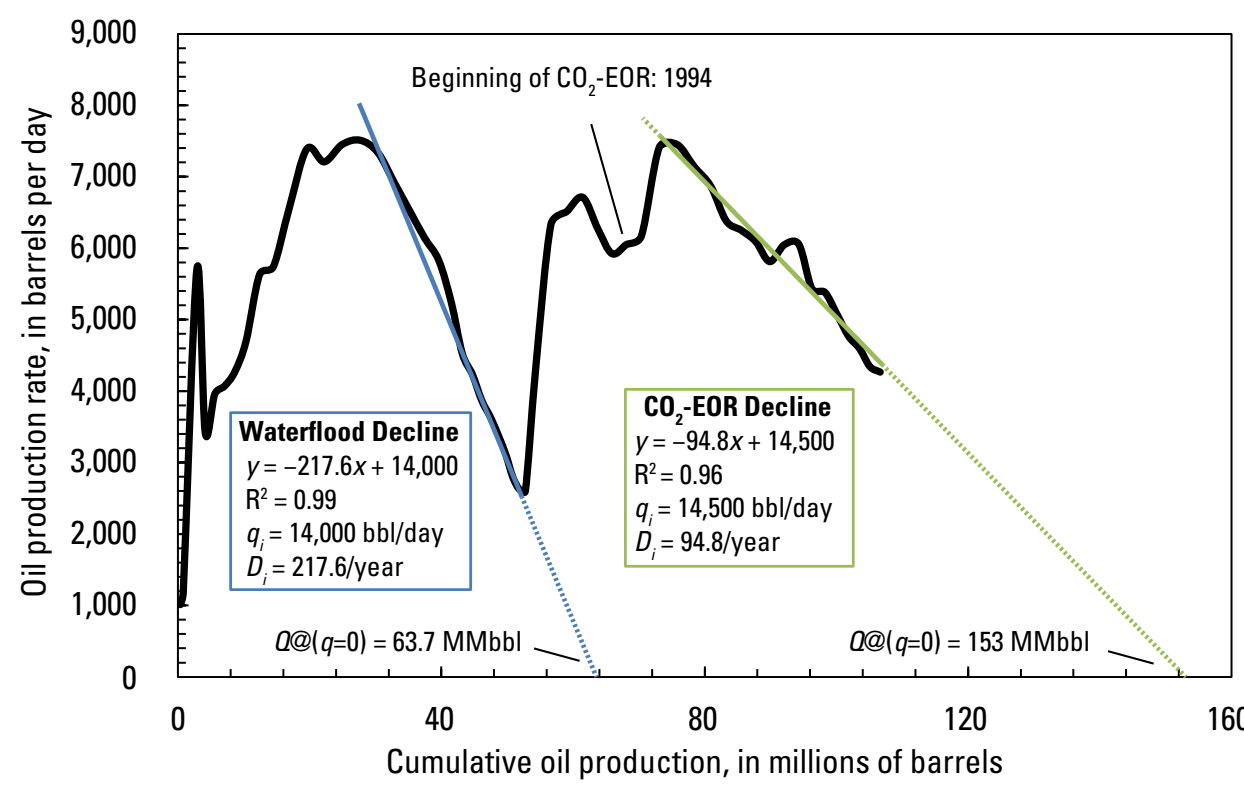

\section{EXPLANATION}

Historical oil production

Waterflood decline trend-Dashed where extended

- $\mathrm{CO}_{2}$-EOR decline trend-Dashed where extended

Figure C1-13. Graph of the oil production rate versus the cumulative oil production for the San Andres Limestone in the Cedar Lake oil field, Texas, showing the decline trends for both the waterflood and the carbon dioxide enhanced oil recovery ( $\left.\mathrm{CO}_{2}-\mathrm{EOR}\right)$ phases. Data are from IHS Inc. (2012). Terms are as defined for figure C1-1. 


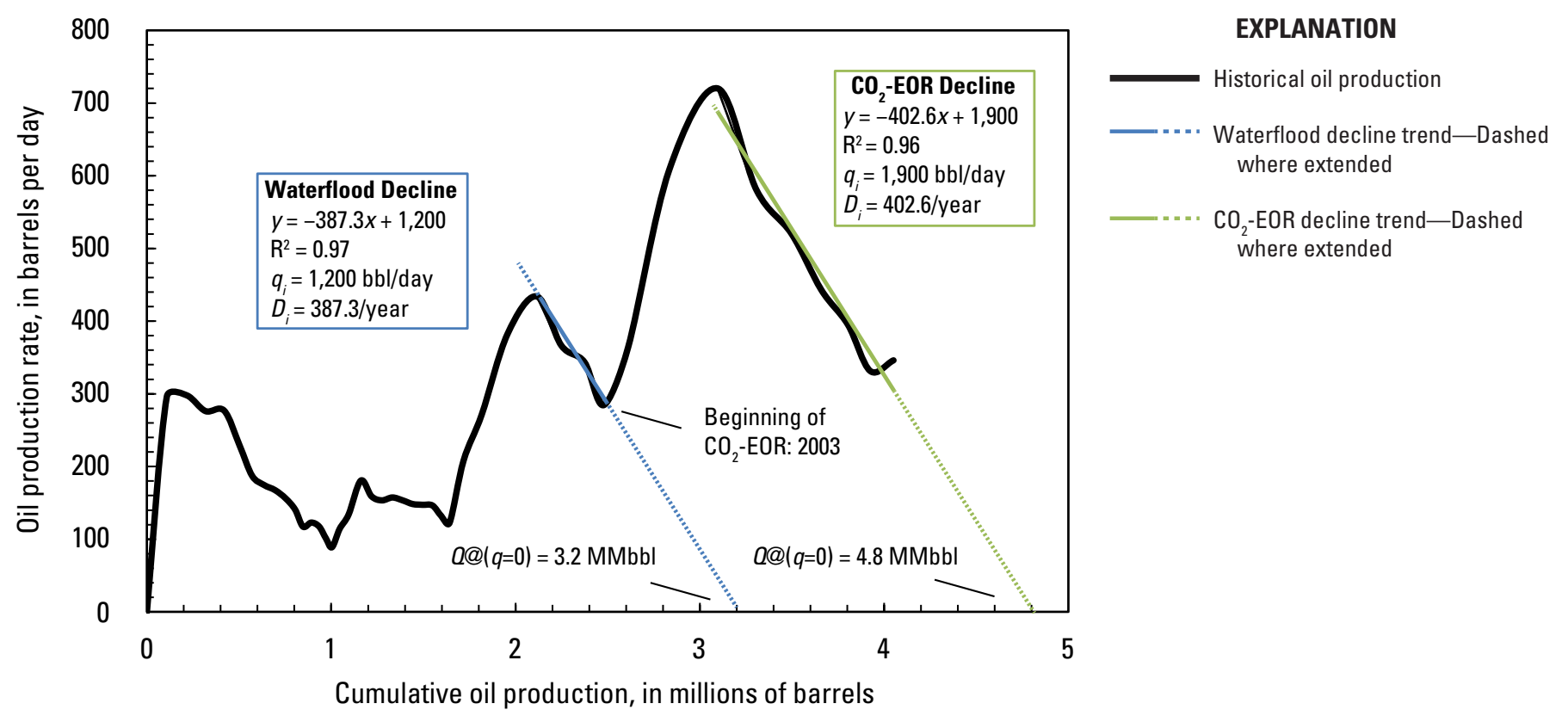

Figure C1-14. Graph of the oil production rate versus the cumulative oil production for the San Andres Limestone in the North Hobbs oil field, New Mexico, showing the decline trends for both the waterflood and the carbon dioxide enhanced oil recovery $\left(\mathrm{CO}_{2}\right.$-EOR) phases. Data are from IHS Inc. (2012). Terms are as defined for figure C1-1.



Figure C1-15. Graph of the oil production rate versus the cumulative oil production for the San Andres Limestone in the Yates oil field, Texas, showing the decline trends for both the waterflood and the carbon dioxide enhanced oil recovery $\left(\mathrm{CO}_{2}-\mathrm{EOR}\right)$ phases. Data are from IHS Inc. (2012). Terms are as defined for figure C1-1. 